\title{
Multimodal Narration of Present Chinese Cultural Relic TV Programs_-Take National Treasure as an Example
}

\author{
Duanli Wu, ${ }^{1,2, a}$, Weihua Chen ${ }^{1, b}$ * \\ ${ }^{1}$ College of Chinese Language and Literature, Hunan University, Lushan South Road, Changsha, China \\ ${ }^{2}$ College of Foreign Languages, China Three Gorges University, Daxue Road, Yichang, China

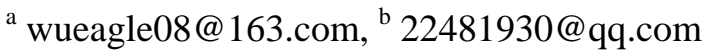

Keywords: National Treasure, cultural relic programs, multimodal narration innovation, culture construction

\begin{abstract}
Mainstream TV programs on Chinese cultural relics are either too serious or superficial, and they do not show the cultural appeal of cultural relics well, and the consistency between the theme and the cultural core. The National Treasure, broadcast by CCTV in 2017 to 2018, is widely praised with the characteristics of "elegant but popular", which reflects the innovation and transcendence of similar programs. With a confident attitude of cultural construction, the program has successfully explored the artistic epitaxy tension of the narration of film and television programs and made three-dimensional and vivid ritual rendering of the Chinese culture of the relics through the integration and innovation of various modes of narrative techniques such as opening, action, music, scenery and colour. The narrative language of the program also fully reflects the Chinese cultural elements, and consciously grasps the core of "people" behind the cultural relics, which conforms to the cultural orientation of the program and makes the program meaningful and interesting. This positive exploration also opens a new window for the dissemination of Chinese classical culture to the world through films and television works on Chinese elegant theme.
\end{abstract}

\section{Introduction}

In recent years, the cultural TV programs such as Lecture Room, The Chinese Poetry Conference, Letters Alive, Readers, I am Speaker, The Chinese Restaurant have been popular, the series of documentaries about "Chinese people" produced by BBC have also been popular around the world. For China, which is rather rich in cultural relics, Chinese cultural relics TV programs have also become a new fulcrum for the global dissemination of Chinese culture and a new window for the world to understand China. While because of the coldness and seriousness of cultural relics, those programs are lack of narrative innovation. Although focusing on the cultural content, these programmes tend to imitate each other`s narrative techniques and are limited to a simple mode ${ }^{[1]}$. The two extremes of high elegance and entertainment are obvious, thus some hot programs have even been suspended. While the National Treasure caught 9.2 points on Douban ${ }^{\text {[2] }}$ and made a breakthrough in this field, it successfully achieves the "elegant but popular" effect by mining the vitality and tension of multi-modal narration techniques of audio-visual art. The academic field confirms the Chinese culture content mostly on the diffusion effect, culture significance, modern technological assistant, tourist effect, etc. While researchers do not pay sufficient attention to the multi-modal narration and culture construction [3] [4] [5] [6] [7] [8], and we could find that National Treasure is neither a documentary emersion of cultural relics, nor a certain TV program narration pattern. Instead, it is a multimodal narration and culture construction on the "culture" and "people" behind the cultural relics from the national emotion and innovation, which exhibits the the vitality and appeal of the cultural relics programs. The program gets rid of the solemn and serious sense of the National Treasure Archive, and has faded the excessive entertaining tendency of some cultural relic programs limited to "exhibition treasure" and " antique evaluation ". It embodies the tension of multimodal narrative and the cultural construction efforts in the art of film and television. In today's global culture communication, its production orientation and techniques are worth our consideration. 


\section{Infectious Multimodal Narrative Innovation}

The TV programs today are not restricted to the traditional narrative pattern like Louis and Auguste Lumiere documentary filming, which mostly relies on simple setting and narration of the host or voice-over. Rather, it is more likely to be "a communication phenomenon applying multisenses, like auditory sense, visual sense and touch sense, through the mixture of multi-methods or multi-codes of image, language, sound, action, etc." ${ }^{\text {[9] }}$ This multimodal narration is based on the socio-semiotics and Systemic-Functional Linguistics (SFL) of M. A. K. Halliday in the late of last century. It spreads the research field of the discourse analysis to the other domains besides parole, which is to spread the single pattern of discourse analysis to multimodal discourse analysis. Gunather Kress and Van Leeuween (Visual Grammar, VG, 1996) ${ }^{[10]}$ believed multimodal discourse is a discourse that mixes multi-communication patterns to send a massage. For TV programs narration, this multimodal discourse includes the narrative techniques of talk show, gala evening, stage play, documentary, etc.

Arising in the 20th century, with the artistic multi-layer, narrative modality and great audiovisual appeal, the audio-visual carrier has replaced the two-dimensional paper carrier as a new path of cultural diffusion, and brings the vitality into the Chinese culture global diffusion.

There have been several cultural relics TV programs focusing on the museums before the National Treasure. Take the Palace Museum, the museum "facing the 600th anniversary" as an example, CCTV has already shot three thematic programs: The Palace Museum (2005), I Mend Cultural Relics in The Palace Museum (2016) and National Treasure (2017). The Palace Museum takes over-voice, 3D image as the major narrative techniques, and supplemented with background music. The documentary I Mend Cultural Relics in The Palace Museum narrates through camera record and dialogue, which reflects some innovation while still in the documentary domain. National Treasure mines the multi-modal narration techniques of prologue, action, music, setting, colour, and other modalities and gives rise to the greater degree of freedom in culture symbol construction, and artistic infectivity.

\subsection{The Quaint Music Mode}

As a typical multimodal discourse, the narrative language of television works may not be directly involved in the narration of the content, but also play the role of rendering the narrative atmosphere and enhancing the emotional resonance of the narrating recipients. Modern TV programs attach great importance to the use of music mode, not only to attract the audience, but also to promote the narrative performance of the guests on the scene through emotional guidance. However, most of the programs tend to use modern music, largely due to the difficulty of musical instruments choosing, performers, music movement, and playing is relatively low, and more suitable for the "Fast Food" narrative mode of today's programs. While National Treasure holds its own style and invites professional music production team for the background music. It does adopt a lot of musical modality to promote the program narration on the one hand, but also shows its own innovation in the musical instruments, style and appeal on the other hand.

Take the majestic opening music Elephant King March for example, it is widely used in every part, and does not directly participate in the narration, but with the magnificent visual effect of the special screen changes, it effectively highlights the artistic appeal of Chinese culture. The music adopts magnificent Tibetan style Tuba as an opening performance, accompanied with drum and Zheng, with the rhythm stepping upward and catching people`s heart. The Tibetan Tuba plays the roaring of the Elephant King, and Elephant King embodies the solemnity and wisdom as the noble symbol of Buddhism. The three instruments are performed together like sun rising or the peaceful world arising, which well coordinates with the cultural atmosphere of the relics TV program.

In the interpretation of the third period of "Moiré Copper Prohibition" story, the empty voice of the Xiao (the Chinese bamboo flute) and violin is Zi Geng's helplessness, and the sound of the loud bell is his awakening, the rhythm of the piano is his warning to the later generations. The artistic value of cultural relics is no longer the only object that the narrative language points to, and the meaning of cultural relics for "human beings" has been sublimated. Other accompaniment refined 
music such as "Wind and Pine", "Qing Ping Music", "Fixed Wind and Wave" and other quaint styles, do not adopt the magnificent modern music, thus they not only raise the artistic character of the program, promote the guests' appearance, but also strengthen the ritual appeal of the program, and stir up the cultural reverence of the audience.

\subsection{Elegant and Gorgeous Scenery Mode}

The scenery of the program reflects the positioning of the narrative style of the program and promotes the visual presentation of the narration, which has always been valued by TV programs. Children's programs would naturally conform to the interests of the children, and the scenery of cultural relic programs should not only match the characteristics of the cultural relics in a solemn style, but also pay attention to the innovation of the gorgeous aspects, in order to meet the aesthetic needs of the contemporary audience, especially the young generation. The application of colourful scenery has always been the focus of TV programming. But the mainstream TV programs generally use static scenery, that is, in the whole process of narration, the scenery maintain still, even the content and colour are seldom changed. It is more passive to play the role of the display of the program environment, rather than to render the narrative atmosphere actively with its own transformation, or directly involved in the narration. The dynamic projection, especially the image and movement of the hanging cylindrical screen of the sky rail, is a new approach adopted by the variety show in recent years. The famous Chinese art show Spring Festival Gala Evening adopts this background narrative mode. The National Treasure caters to the trend of this dynamic setting mode, and embodies its own innovation in the design of dynamic scenery.

The stage background design of National Treasure is not a two-dimensional level of visual distribution, but the four levels of visual focus from inside. These four visual levels are mainly realized by the visual focus of the yarn box projection, the visual presentation and movement of the column screen, the visual background and magnifying effect of the giant LED ring screen.

The center of stage vision is realized by yarn box cube projection, creating an independent and mysterious focal stage space. At the beginning of the program, it is the display platform of four characters of "national treasure", playing the role of strengthening the program name card. In the "national treasure debut" part, it reproduces the image of the national treasure and plays a role in strengthening the content of the program. In the presentation of the story of "the legend of former generation", the combination of yarn box and projection forms the core space of stage performance, which plays a role in strengthening the narration of programs.

The complex sky rail hanging screen can realize the three-dimensional projection of the image, let the audience in every corner could enjoy the real scene of the cultural relics intuitively. It moves according to the narrative plot requirements, or presents the narrative scene or renders the narrative atmosphere as well. There are 9 tracks above the column screen, each of which has a transparent LED screen with 1 square meter of square meters at the bottom and 6 meters high. Through the numerical control windlass, the column screen can be lifted and moved singly or together. With the transparent picture presented and the magnificent background changing, the multidimensional and three-dimensional stage space of "inside and outside", "virtual and real", "front and post", "front and post" and "vulgarity and elegance" are constructed. Moreover, through the position adjustment of the stage transparent column screen, the construction of the program scene environment and the transformation of the scene could be skilfully completed. The screen change of the drama stage is perfectly embedded in the variety show mode in a fluent and natural way. In the transition of "National Treasure Appearance" and "Time-space Crossing" parts, the adjustment of the stage column screen has created a link scene with great sense of ritual and impact, which has become the most unique part of the program. Different from the usage of cylindrical screens in ordinary evening shows for achieving a softer and festival atmosphere, the National Treasure has used the long cubic column screen innovatively to facilitate the construction of the small stage for "the legend of former generation " performance, and also to highlight the masculinity of Chinese culture and the historical story behind the cultural relics.

The extension of the stage is represented by a giant LED ring screen with a length of 43 meters 
and a height of 7 meters. In the narration of hosts and the guests, the ring screen acts as a visual foil to prevent the column screen from being too empty. In the display of the content of the cultural relics, the content elaborately tailored for each piece of cultural relics on the ring screen are clear, majestic, colourful and gorgeous, letting people seem to enjoy the personal visit in the museum, and to present a beautiful visual feast through the ancient and modern time for the audience.

\subsection{D Restore Image Mode of Near Distance Sense}

The application of 3D to restore image modality is not the original creation of National treasure. Prior to that, the documentary Imperial Palace, which used more 3D technology, restored the Imperial Palace's ancient architecture. But National treasure adopts the 3D technology bravely to display the cultural relic both in itself and the program narration. At every opening, the program is aiming at the three-dimensional symbol of the program - the four words of the name. The symbol is presented in front of the audience by simulating the melting and forming of the metal, thus forming a sense of cultural ritual in the image.

Although the national treasures are all well preserved cultural relics, many of our cultural relics are incomplete due to wars and accidents. Take the ninth show for example, the Porcelain Pagoda of Nanjing Great Buddhist Temple, only one arch was left. It not only represents the highest peak of the ancient Chinese pagoda art, but also enjoys a high reputation in the western world. It is difficult to let the audience admire its grandeur and beauty only by graphic display or abstract interpretation. The program used the 3D technology as was in Imperial Palace thirteen years ago to restore the tower. It combines the interior and exterior scenes, and the close lens and far lens intersecting narrative techniques that truly restore the ancient architecture reaching clouds, with glaze and the Buddhist ever-light. In fact, this kind of 3D image is also used in a large amount of precious cultural relics well preserved but not suitable for displaying on the spot, such as "Picture of Side Tower and Guarding". Thus the audience can intuitively feel the artistic charm of the cultural relics.

\subsection{The Value and Reflection of Multimodal Narrative Innovation for Infectivity}

Under the combined elements of innovative narrative music, scenery and 3D images, the audience not only has a ritual visual perception of the cultural relics, but also leads to the same inner fluctuations of the audience in front of screen, forming a multi-level interaction effect on the cultural relic stories. It reflects the "people oriented" narrative feature of focusing human story behind the cultural relics and the acceptance of the audience, and promotes the acceptance and dissemination of cultural relics.

Of course, the multimodality narrative innovation has created the attraction of the program to the audience, and also brought huge workload and some mistaken details. People pointed out that some actors' ancient costumes did not conform to ancient regulations, or the program lacked professionalism. However, we should also recognize that the program can obtain such a wide cultural identity, just because it does not position itself as a professional cultural relic documentary, but a program of culture communication. In fact, "seeking truth" or "seeking beauty" has always been a difficult problem in cultural communication. "Seeking truth" is rigorous, but it will be "high while little popularity". "Seeking beauty" is distorted, but it is easy to get the general audience's interest and identity. The paradox of "seeking truth" and "seeking beauty" is actually the assurance of the needs of the recipient of culture. From the practice of cultural communication and communication in the last few centuries, the decision of the success or failure of cultural communication depends largely on the culture acceptor, not the exporter. The focus of cultural relics and cultural programs should not be on the program 's position and willingness. The television industry needs to balance the dialectical relationship between the entertainment and cultural responsibility of cultural programs. It is cultural confidence that we should take into full consideration. We also should think about what the audience wants to accept, what they can accept, and how to accept it. It can be concluded that the innovation of the narrative strategy of the National Treasure is also the proper content of the cultural programs emphasizing culture acceptor, and thus make it popular among the audience. 


\section{Multimodal Narrative Language Coordinating with Cultural Orientation}

The cultural attraction of the cultural relics program is not simply to attract audience; in fact, the entertainment programs focusing on the "price of cultural relic" can attract many viewers. However, the cultural attraction should not only take the interests of the audience by choosing a lower level of culture, but rather, through the conscious construction of the culture to reveal a certain classic culture, so that a cultural respect and appeal of the recipient is called upon, which is the purpose of culture spread. Jinsheng Liao and Xiao Ma point out that in recent years, although Chinese TV programs attach great importance to the appeal to the general audience, there has been an extreme trend of "superficial" and "vulgar", whose essentially lies in the "spiritual abandonment" of the programs $^{[11]}$. National Treasure did not reduce the cultural elegance of the program excessively, nor did it lose its appeal to the common people. It realized the appreciation of both the refined and the vulgar, which coordinate with the cultural spirit of the program.

\subsection{Self-deprecating and Confident Lines}

The opening speech of a host is a language commonly used in TV programs. It often points out the subjects of the narrative with the concise words and seizes the heart of the audience. Modesty often derives from self-confidence. National Treasure opens with: "with such a fancy start, you can tell this is a show at its early stage. How young we are, that is, 5000 years or so ", seems to be off the topic of the program, but with the self-confidence of Chinese culture as the bottom line. The Chinese narrative language distinguishes itself from the tradition of Western cultures. The Five Patterns from the Spring and Autumn Period advocated by Chinese classics are "detailed while intended, implicit while profound ". This kind of implicit language, with an eloquent voice, and a melodious and tearful music, especially the deliberate pause of No. 001 Guoli Zhang after saying "how young we are" every time, like questioning and answering himself. Self-humbling is full of confidence. Danling Liu believes that "an image piercing point that arouses emotional stimuli, emotional tremors, emotional resonations, emotional associations, and emotional identity is more likely to attract selective attention from the public, naturally send them an invitation, leaving them a profound and lasting impression and the foundation of cultural identity and emotional memory. “ TV programs emphasize the attraction of art and the appeal of the mind. Such bold lines arouse the audience's sense of cultural identity and pride, and the psychological distance from inside and outside the screen. Covering the music, background, action, and the multimodal opening of the show, it has played the role of "self-confidence invitation" of "image piercing point". ${ }^{\text {[12] }}$

It is not only the introductory lines of the host, but also the lines of the invited stars permeable with cultural heritage and rich meaning. Tony Leung, a famous Hong Kong actor invited by the first phase of the program, told the story of his coming to the Imperial Palace to shoot the screen in 1982, and then lamented that "the words of many countries have died out, but the vitality of Chinese characters has last for thousands of years... People are really small in front of those characters, which, however, make people great.” The simple and plain language contains the endless growth of our great words and the tenacity and greatness of the Chinese nation, just like those characters.

\subsection{Body Movement Respect Chinese Culture}

As a program to disseminate cultural relics, the mode of action of narration should be modest. It should also convey the reverence for cultural heritage. For example, the Sima Guang, played by the film emperor Tony Leung in the former legend of "Shigu", accompanied by the sad music of the scene, his words, the screwed eyebrows, the gazing eyes, and the proper action, all show his missing to his father and the worries about the future of the Song Dynasty.

The program does not use the traditional TV program narrative mode that lets the guardians recount their views on cultural relics statically, but adds the two dynamic parts of the guardians entering the museum and the playing the story of the cultural relic to show their own perception. Lei $\mathrm{Yu}$, director and producer of the program pointed out that the exclamation, emotion and excitement of the "Guardian" after understanding the cultural relics will also cause the audience's exclamation, emotion and excitement ${ }^{[13]}$. In the second phase, Gang Wang's meticulous observation and worship 
of "Ceng Houyi's Clock", especially the feature of his eyes, made us truly feel the artistic shock of the cultural relics. In the former legendary of "the arch gate of the Porcelain Pagoda of Nanjing Great Buddhist Temple", when Hailu Qin played the embroidered maid Song, her eyes dripped her tears and expressed her sincere feelings about the story of the vicissitudes of cultural relics.

The National Treasure has arranged a large number of young audiences on the scene through the colourful stage play which is more easily accepted by the young people. Through their expressional movements, a considerable number of young people have been effectively attracted. For example, Jackson Yi was invited to serve as the "Guardian" of the Dake Tripod; the camera is more given to the audience, their eyes, tears, and excitement, melting the alienation of the screen, and giving young viewers more opportunities to communicate with the heart. "When Jackson Yi appears in the program, the focus of the bullet on the screen is not on the handsome star but on the story of generations of Pan Family protecting the national treasures" ${ }^{[14]}$, the story of people surpasses the cultural relics as the focus of young audience. National Treasure takes the audience as the center of the narrative action mode and let the younger generation experience traditional culture and national emotion of the cultural relics through the sense of substitution.

\subsection{Colours Fit Chinese Culture}

Colour also plays the role of narration in TV program. Different from the use of a large number of white, pink, yellow and other light stage colours to relax the atmosphere in the major variety programs, National Treasure mainly uses black, blue and other cold and serious colours to match the solemnity of cultural relics. Both the host and the curator of museum look solemn and steady in cool clothe colours. When the special guests appeared, the light was also obviously dimmed, with the blue ray to highlight the mysterious keynote. However, when the program is transferred from the previous story of the cultural relics to the story of this life, the light is obviously lifted, with white and yellow light to highlight the vivid characteristics of the cultural inheritance in this world.

The use of lighting is also the key content of TV colour mode. The lighting of National Treasure uses special emphasis on the contrast of light and shade to highlight the focus of the vision, shields the disturbing image of the audience, and uses single bright light to strengthen the sense of standing and stability of the visual target from multi-angles. Different from most variety programs are opened with strong light, or brightening in turn. The design of the light in the opening of the National Treasure is turned from dark to bright, accompanied by a flickering light, symbolizes that cultural relics is presented from the unknown to the known. In addition, no matter the in stage performance or in the museum, the light is contrasted with the obvious light and shade, and the illuminance of the surrounding is reduced, to fit the cultural vicissitudes of the national treasure and avoid the brilliant light affecting the display of the treasure. The program mainly adopts stable and pure light to match of the stage performance, and does not interfere with the audience's appreciation of the cultural relics and stories on TV screen, so as to achieve "quiet" and "clear" effect. Take Gou Jian`s Sword for example, as the "best sword of the world", a multi-angle light is used to make the metallic lustre more obvious, and the whole body more stereoscopic and charming.

\section{Conclusion}

The success of National Treasure lies not in its simple reproduction of China's ancient cultural relics, nor in its use of certain TV program narrative methods to spread Chinese traditional culture, but in the multimodal narration from the perspective of national emotion and innovation consciousness, and in the active construction of the culture core of the program. Compared with similar programs, it boldly combines TV interview, evening party, stage play, documentary and other film techniques, fully explores the tension of various narrative modes ,such as language, action, music, image and so on. It creates a strong artistic appeal in the construction of cultural symbols of the program, which has significantly surpassed the mainstream cultural relic programs. The program fully reflect the unique charm of Chinese cultural elements, and consciously grasp the theme of "culture" and "people" behind cultural relics, which conforms to the inner cultural orientation of the program and highlights the vitality and attraction of cultural relics programs. In 
line with the aesthetic needs of contemporary audiences, National Treasure has successfully balanced the cultural elegance and popularity, avoided the two production tendencies of "elegant but unpopular" and "sensationalism" which are only on the consideration of either content or the audience, and also caused a social upsurge in appreciation of cultural relics, which opens a new pattern of cultural communication based on cultural confidence. It can be seen from the exploration of National Treasure that cultural relic TV programs can also achieve a good communication effect of "songs of a highbrow type could also find many people to join in" through bold multimodal narrative innovation and cultural construction, which is of great significance to the global dissemination and acceptance of Chinese traditional elegant culture on film and television carriers.

\section{References}

[1] Douban is an Chinese large and influencial wesite, provides introduction, grade and comment on various audio-visual works. The date was cited on March $30^{\text {th }}, 2018,54181$ people grade.

[2] Wang, J., Let "National Treasure" Hit. People's Daily, December 28, 2017

[3] Zhang, Y., National Treasure Detonated Museum Treasure Tour of Museum. China Travel Newspaper, January 9, 2018.

[4] Mu, H., (February 27, 2018) National Treasure: Opening a Unique Way to Open the Museum. Liberation Daily.

[5] Ma, L.X. \& Liu, L., (March10, 2018) A Cultural Program to Stimulate the Three Education Gene. China Education.

[6] Qin D.H., (February 15, 2018) Culture + Technology, Presented a Rich Spring Festival Culture Meal. Chinese Culture Daily.

[7] Wu Q.M., (December 15, 2017) National Treasure Opened the Tradition with Fashion. Hunan Daily.

[8] Yu Y.B., (2018) The Success Factors of National Treasure and Tts Enlightenment to Cultural Inheritance. China Television, (5), 36-39.

[9] Zhang, D., (2009) Exploration of the Comprehensive Theoretical Framework of Multimodal Discourse Analysis. Chinese Foreign Language, (1), 24.

[10] Kress, G. R. \& Van Leeuwen, T., (1996) Reading Images: The Grammar of Visual Design. Psychology Press: London.

[11] Liao, J.S. \& Ma, X., (2017) The Change of China's TV Culture Characterization. Editors' Friend, (6), 41-47.

[12] Liu, D., (2017) Making Consensus: Image Building Strategy of Chinese Image. Zhongzhou Journal, (10), 161-167.

[13] Li, C. \&Yu, L., (January 18, 2018) Tells the Story of the National Treasure with Chewy and Lingering Aftertaste. Chinese Women's Daily.

[14] Wang, Y., The Modern Moment of Cultural Relics, We Touch the Best Times of History. Wen Wei Po, February 14, 2018. 